Poot, E.P., Bruijne, M.C. de, Wouters, M.G.A.J., Groot, C.J.M. de, Wagner, C. Exploring perinatgh shift-to-shift handover communication and process: an observational study. Journal of

\begin{tabular}{|l|l|}
\hline $\begin{array}{l}\text { Postprint } \\
\text { Version }\end{array}$ & 1.0 \\
\hline Journal website & http://onlinelibrary.wiley.com/doi/10.1111/jep.12103/abstract \\
\hline Pubmed link & $\underline{\text { http://www.ncbi.nlm.nih.gov/pubmed/24354710 }}$ \\
\hline DOI & $10.1111 /$ jep.12103
\end{tabular}

This is a NIVEL certified Post Print, more info at http://www.nivel.eu

\title{
Exploring perinatal shift-to-shift handover communication and process: an observational study
}

\author{
Else P. POOT RN MSCN JUNIOR RESEARCHER ${ }^{1, *}$, MARTINE C. DE BRUIJNE MD PHD \\ Associate ProfESSOR ${ }^{1}$, MAURICE G. A. J. WOUTERS MD PHD GYNAECOLOGIST ${ }^{2}$, \\ CHRISTIANNE J. M. DE GROOT MD PHD GYNAECOLOGIST, PROFESSOR ${ }^{2}$ AND CORDULA \\ WAGNER MA PHD PROFESSOR ${ }^{1,3}$ \\ ${ }^{1}$ Department of Public and Occupational Health, EMGO+ Institute for Health and Care \\ Research, VU University Medical Centre, Amsterdam, The Netherlands \\ ${ }^{2}$ Department of Obstetrics and Gynaecology, VU University Medical Centre, Amsterdam, \\ The Netherlands \\ ${ }^{3}$ Netherlands Institute for Health Services Research (NIVEL), Utrecht, The Netherlands
}

\begin{abstract}
Rationale, aims and objectives: Loss of situation awareness (SA) by health professionals during handover is a major threat to patient safety in perinatal care. SA refers to knowing what is going on around. Adequate handover communication and process may support situation assessment, a precursor of SA. This study describes current practices and opinions of perinatal handover to identify potential improvements.

Methods: Structured direct observations of shift-to-shift patient handovers $(n=70)$ in an academic perinatal setting were used to measure handover communication (presence and order of levels of SA: current situation, background, assessment and recommendation) and process (duration, interruptions/distractions, eye contact, active inquiry and reading information back). Afterwards, receivers' opinions of handover communication $(n=51)$ were measured by means of a questionnaire.

Results: All levels of SA were present in 7\% of handovers, the current situation in $86 \%$, the background in $99 \%$, an assessment in $24 \%$ and a recommendation in $46 \%$. In $77 \%$ of handovers the background was mentioned first, followed by the current situation. Forty-four per cent of handovers took 2 minutes or more per patient. In 52\% distractions occurred, in $43 \%$ there was no active inquiry, in $32 \%$ no eye contact and in $97 \%$ information was not read back. The overall mean of the receivers' opinions of handover communication was 4.1 (standard deviation \pm 0.7 ; scale $1-5$, where 5 is excellent).
\end{abstract}


Poot, E.P., Bruijne, M.C. de, Wouters, M.G.A.J., Groot, C.J.M. de, Wagner, C. Exploring perinatah shift-to-shift handover communication and process: an observational study. Journal of Evaluation in Clinical Practice: 2014, 20(2), 166-175

\begin{abstract}
Conclusions: Perinatal handovers are currently at risk for inadequate situation assessment because of variability and limitations in handover communication and process. However, receivers' opinions of handover communication were very positive, indicating a lack of awareness of patient safety threats during handover. Therefore, the staff's awareness of current limitations should be raised, for example through video reflection or simulation training.
\end{abstract}

\title{
INTRODUCTION
}

Prompted by higher perinatal mortality rates compared with other west European countries [1, 2], patient safety is a major issue in obstetrical care in the Netherlands. The care for labouring women in the Netherlands is characterized by a high rate of handovers, for example between primary, secondary and tertiary care, but also intradepartmental and shift to shift [3]. Handovers have been indicated as an important threat to patient safety in obstetrical care $[4,5]$ and also in several other settings in health care [6-9]. A major cause of failure in handovers is loss of 'situation awareness' (SA) [10-13]. SA refers to knowing what is going on around a person based on various sources of information. SA consists of three levels. The first level is the perception of acquired information; the second is comprehension, which is based on the integration of the acquired information using clinical knowledge; and the third is the projection into future events [14]. In general, having an adequate SA is important because it is the main precursor of decision making, and hence performance of action [14].

Handover is a complex process [15] that serves diverse functions of which the communication of information is the most important [16]. Handover can be characterized by a receiver establishing SA based on the information given by a sender. This is also known as team SA, which is 'the degree to which each team member possesses the SA required for his or her responsibilities' [17]. The handover literature is characterized by the focus on standardization and effectiveness of information [16, 18]. Recently, non-technical skills (or human factors) such as communication and teamwork, have been included as a supplementary focus of handover [19-24]. However, only one study measured SA through the appropriate identification of patients needing attention [19].

The process to establish SA, known as situation assessment, can be influenced by the inability to integrate information or to focus attention [14]. Therefore, an adequate handover should support situation assessment. The way information is communicated during handover affects situation assessment [17]. Moreover, it is proposed that handover in a standardized order contributes to an adequate handover [18]. Also, several process factors have been put forward as effecting an adequate handover [25] including duration [26, 27], interruptions/distractions [26, 28, 29], absence of active inquiry, absence of eye contact between sender and receiver [28], and not reading information back [10, 22]. Finally, high workload [7, 14, 30] and limited clinical experience [14, 27, 31] have been described in relation to an adequate handover.

In order to improve the safety of perinatal handover by tailored interventions [32, 33], we aimed to study current shift-to-shift handover communication and process as 
Poot, E.P., Bruijne, M.C. de, Wouters, M.G.A.J., Groot, C.J.M. de, Wagner, C. Exploring perinatgh shift-to-shift handover communication and process: an observational study. Journal of

Evaluation in Clinical Practice: 2014, 20(2), 166-175

well as receivers' opinions of handover communication afterwards. We conducted a mixed-methods observational study in a perinatal setting during day shifts to answer the following research questions: (1) How is handover communication executed during perinatal shift-to-shift handovers regarding the presence and order of all levels of SA? (2) How does the handover process evolve regarding duration, interruptions/distractions, presence of active inquiry, eye contact and read back? (3) What are the receivers' opinions about the presentation, clarity and completeness of handover communication directly after handover?

\section{METHODS}

\section{Study design, setting and study objects}

The study was conducted in a six-bed labour ward in a tertiary hospital setting. Structured direct observations were used to explore perinatal handover communication and process in relation to situation assessment. During shift-to-shift handover meetings, verbal handovers of individual labouring women admitted to the labour ward $(n=70)$ were observed, because they took place at a scheduled time and a fixed place. The handovers concerned both medical $(n=30)$ and nursing $(n=40)$ handovers from night to day shift (morning handovers), and from day to evening shift (afternoon handovers). Medical and nursing handovers took place separately, but approximately at the same time $(0800 / 1700$ and $0730 / 1445 \mathrm{~h}$, respectively). Medical handovers were attended by gynaecologists, residents and clinical midwives. Usually, the handover of patients was carried out by the junior doctor. Nursing handovers were attended by obstetrics and gynaecology nurses, obstetrics and gynaecology nurse trainees, and registered nurses. Usually, patients at the labour ward were handed over by the obstetrics and gynaecology nurse (trainee). Handovers were observed from 6 October 2011 until 10 November 2011. During the observation period, the researcher attended two to three handover meetings per day from Monday to Friday. Receivers' opinions of handover communication of each patient handover were measured directly after the handover meetings by means of a written questionnaire. Also directly after the handover meetings, the senders were asked to assess the workload of the shift preceding the handover meeting. Finally, clinical experience of the senders was assessed.

\section{Measures}

Handover communication and process were measured through direct observations. Observations were carried out by one researcher (EP) using a checklist adapted from an earlier research [34], which was designed for the observation of verbal communication of individual patients during ward rounds. An observation protocol was developed in which the definitions and examples of the observable items of handover communication and process were described (see Box 1). The observation protocol was fine-tuned during the observation period by adding examples to the definitions.

\section{[Box 1.]}


Poot, E.P., Bruijne, M.C. de, Wouters, M.G.A.J., Groot, C.J.M. de, Wagner, C. Exploring perinatgh shift-to-shift handover communication and process: an observational study. Journal of Evaluation in Clinical Practice: 2014, 20(2), 166-175

Handover communication was measured through observing the presence and order of the following elements: situation, background, assessment and recommendation (SBAR). SBAR is a framework for verbal communication between health care professionals about a patient's situation. SBAR logically structures the information in a predictable way [18, 35, 36]. It is presumed that SBAR supports situation assessment because it is in accordance with all levels of SA. Situation and background refer to the perception of information (level 1), assessment to the interpretation of information (level 2) and recommendation to the planning of future events (level 3). During each patient handover, the presence of each SBAR element was scored as well as their consecutive order. If elements were repeated, numbering was continued. For example, if the order was background, situation, background, assessment, number 1 was noted for background, number 2 for situation, number 3 for background and number 4 for assessment.

Handover process was measured through observing the duration (in four categories), presence, number and nature of interruptions/distractions, having/making eye contact between senders and receivers, and active inquiry. Active inquiry was measured by observing if questions were asked by the receivers.

Receivers' opinions of handover communication were measured on a self-developed six-item written questionnaire. The six items were: information is complete, information is presented in an orderly manner, essential issues are present, information is clear, no unnecessary issues are present and actions are clear. The items were formulated in statements and were measured on a scale from $\mathrm{A}=$ 'strongly disagree' to $\mathrm{E}=$ 'strongly agree'. For determining overall receivers' opinions of handover communication, a composite variable was computed reflecting the mean of the six sub-items and using the data of the sub-items as numerical data $(A=1$ to $E=5)$. Workload was measured using the validated NASA-TLX instrument, a widely used multidimensional scale to assess workload. We measured mental, physical and temporal demand and omitted the three other items to reduce the burden for respondents. These items were chosen because they reflect the taskrelated objective factors of the instrument [37]. Finally, clinical experience of the senders and receivers was measured by number of years of working experience in obstetrical care, using four categories.

\section{Analysis}

Frequencies were used to describe handover communication and process and receivers' opinions of handover communication. Chi-square analysis was used to assess statistical differences for type of handover, time of handover, and clinical experience and workload of senders. To assess mutual relations between handover communication and process and receivers' opinions of handover communication, both univariate and multivariate analyses were used. For univariate analysis, chisquare analysis was used. Fisher's exact test was used if the analysis revealed that the data were unequally distributed across the cells of the table [ $>20 \%$ of cells with a cell count less than five, or one or more cell(s) with a cell count of less than one] because of the relatively small sample size. Because the data of overall mean of receivers' opinions of handover communication had a skewed distribution, Mann-Whitney or Kruskal-Wallis was used to assess statistical differences for type and time of handover, handover communication and process, and also for clinical experience and workload of senders. If univariate analysis revealed that a variable was related to two 
Poot, E.P., Bruijne, M.C. de, Wouters, M.G.A.J., Groot, C.J.M. de, Wagner, C. Exploring perinatałh shift-to-shift handover communication and process: an observational study. Journal of Evaluation in Clinical Practice: 2014, 20(2), 166-175

or more variables, these variables were used as determinants for multivariate logistic analysis, using a backward method, in order to fit the best model. The Wald test was used for the selection of determinants. Analyses were performed using the Statistical Package for the Social Sciences (SPSS) 20.0 (IBM Corp., Armonk, NY, USA). Significant differences were set at $P<0.05$ and for logistic regression at $P<0.10$.

\section{Ethical approval}

The research project was not assessed by the ethics board as the study did not fulfil the criteria of the Dutch Medical Research (Human Subjects) Act, as no patient treatments were part of the study and the psychological impact of observing handovers on the employees was negligible. Furthermore, the measurements were legitimate as they were executed as part of an internally organized quality improvement project.

\section{RESULTS}

\section{Characteristics of handovers}

Seventy handovers of individual patients were observed (Table 1), 43\% of which were medical handovers $(n=30)$ and $57 \%$ nursing handovers $(n=40)$. Of all handovers, $40 \%$ occurred in the morning (night to day shift; $n=28$ ) and $60 \%$ in the afternoon (day to evening shift; $n=42$ ). Sixty-three per cent of the senders $(n=44)$ and $53 \%$ of the receivers $(n=27)$ had at least 5 years of clinical experience in obstetrical care. Nurses were more experienced than doctors [Fisher's exact 18.179; $P<0.000$ and $\chi^{2}$ trend 17.138; degrees of freedom (d.f.) $\left.=1 ; P<0.000\right]$. During handovers in the morning, senders were more experienced than in the afternoon (Fisher's exact 11.156; $P=0.007$ and $\chi^{2}$ trend 8.163 ; d.f. $=1 ; P=0.003$ ).

\section{[TABLE 1. ]Handover communication}

Handover communication regarding the presence and order of the SBAR elements was observed during 70 patient handovers (Table 2). All SBAR elements were present in $7 \%$ of handovers $(n=5)$, mostly in the order background, situation, assessment and recommendation (BSAR). The background $(99 \% ; n=69)$ and situation ( $86 \% ; n=60)$ elements were most frequently present in all handovers, the recommendation $(46 \% ; n=32)$ and assessment $(24 \% ; n=17)$ elements less frequently. Background following situation $(77 \% ; n=54)$ was the order most frequently present in all handovers. A repetition of the separate SBAR elements was observed in 34\% of all handovers, such as BSBS, BSRBS or BSBSRS. The element assessment $\left(\chi^{2} 4.377\right.$; d.f. $\left.=1 ; P=0.036\right)$ and the order background-situationassessment $\left(\chi^{2}=7.565\right.$; d.f. $\left.=1 ; P=0.006\right)$ were more present in medical handovers than in nursing handovers.

\section{[TABLE 2. ]}

\section{Handover process}


Poot, E.P., Bruijne, M.C. de, Wouters, M.G.A.J., Groot, C.J.M. de, Wagner, C. Exploring perinatgh shift-to-shift handover communication and process: an observational study. Journal of Evaluation in Clinical Practice: 2014, 20(2), 166-175

Handover process regarding duration, interruptions/distractions, presence of active inquiry, eye contact and read back was observed in 70 patient handovers (Table 3). Of all handovers, $44 \%(n=29)$ lasted more than 2 minutes and 52\% $(n=34)$ were interrupted/distracted at least once (Table 3). Most of the interrupted/distracted handovers were interrupted/distracted once. Usually, these were distractions such as health professionals walking in or out, telephones ringing or health professionals answering the telephone. In $44 \%(n=28)$ of all handovers, no questions were asked by the receivers. In about a quarter of all handovers, having/making eye contact was not observable, especially in short handovers and in nursing handovers. Read back occurred in 3\% $(n=2)$ of all handovers. In the afternoon, more handovers were interrupted $\left(\chi^{2} 6.281\right.$; d.f. $\left.=1 ; P=0.012\right)$ and questions were asked in more handovers $\left(\chi^{2} 4.402 ;\right.$ d.f. $\left.=1 ; P=0.036\right)$ than in the morning. Also, there was a trend that handovers in the afternoon were more frequently interrupted $\left(\chi^{2}\right.$ trend 5.542; d.f. $=1 ; P=0.019)$ and lasted longer $\left(\chi^{2}\right.$ trend $4.085 ;$ d.f. $\left.=1 ; P=0.043\right)$ than in the morning.

\section{[TABLE 3. ]}

\section{Receivers' opinions of handover communication}

Receivers' opinions of handover communication were measured directly after the handover meeting by 51 receivers. Overall mean of receivers' opinions of handover communication was 4.1 [standard deviation $(\mathrm{SD}) \pm 0.7$ ] and was somewhat higher in nursing handovers than in medical handovers (mean 4.2 versus 3.9; Table 4), but no statistical difference was detected (Mann-Whitney $U$ 222.5; $P=0.052$ ). Nurses more than doctors appraised handover communication as being clear (Fisher's exact 8.816; $P=0.024)$.

\section{[TABLE 4. ]}

\section{Factors determining handover communication and process and receivers' opinions of handover communication}

Also, mutual relations between handover communication and process and receivers' opinions of handover communication were analysed. There was a trend that the element recommendation was more frequently present if the clinical experience of the senders increased ( $\chi^{2}$ trend 5.094; d.f. $\left.=1 ; P=0.024\right)$. Handovers were shorter if no interruptions/distractions occurred (Fisher's exact 17.230; $P=0.001$ and $\chi^{2}$ trend 14.854; d.f. $=1 ; P \leq 0.000) ; 80 \%(n=24)$ of not interrupted handovers had a duration of less than 2 minutes. Also, handovers were shorter if no questions were asked $\left(\chi^{2}\right.$ trend $5.141 ;$ d.f. $=1 ; P=0.023)$. Overall mean of receivers' opinions of handover communication was higher in handovers that were not interrupted (Mann-Whitney $U$ $198.0 ; P=0.017$ ) and if senders had 1 year or more clinical experience (KruskalWallis 9.171 ; d.f. $=3 ; P=0.027$ ). Handover communication was appraised as being presented in a more orderly manner if handovers were not interrupted/distracted (Fisher's exact 14.246; $P=0.001$ and $\chi^{2}$ trend 4.996; d.f. $=1 ; P=0.025$ ), had a duration of less than 2 minutes (Fisher's exact 9.753; $P=0.011$ and $\chi^{2}$ trend 8.039; d.f. $=1 ; P=0.005$ ) and if clinical experience increased (Fisher's exact 17.398; $P=0.011$ ). There was no relation between the presence of (all) SBAR elements and 
Poot, E.P., Bruijne, M.C. de, Wouters, M.G.A.J., Groot, C.J.M. de, Wagner, C. Exploring perinatah shift-to-shift handover communication and process: an observational study. Journal of Evaluation in Clinical Practice: 2014, 20(2), 166-175

receivers' opinions of handover communication. Furthermore, handover communication was appraised as being more clear in handovers that were not interrupted (Fisher's exact 8.204; $P=0.033$ and $\chi^{2}$ trend 4.364; d.f. $=1 ;=0.037$ ). Additionally, there was a trend that handover communication was appraised as containing more unnecessary issues if questions were asked $\left(\chi^{2}\right.$ trend 4.564 ; d.f. $=1$; $P=0.033)$. Finally, the actions to be performed in the next shift were appraised as being clearer if perceived workload of senders was lower (Fisher's exact 11.361; $P=0.043$ ). The overall mean of receivers' opinions of handover communication and the sub-item 'Information presented in an orderly manner' differed on more than two variables. Logistic regression analyses were performed using a cut-off point of, respectively, $\leq 4.1$ and $\geq$ 'Agree'. A shorter duration of handover predicted that the information was appraised as being presented in a more orderly manner [odds ratio 0.06 (95\% BI 0.007-0.529); Wald 6.423, $P=0.011$; constant 3.178]. In other words, the probability of handover being appraised as presented in an orderly manner is $59.1 \%$, if handover is shorter than 2 minutes.

\section{DisCUSSION}

We assessed handover communication and process and receiver's opinions of handover communication during shift-to-shift handovers of labouring women in a Dutch academic perinatal care unit. Results showed that situation assessment is hampered in several ways. Communication of all levels of SA was absent in 93\% of handovers. Mainly, the level 2 and 3 elements were absent, respectively, in 76 and $54 \%$ of handovers. Handover process showed imperfections because of a relatively long duration (at least 2 minutes) in $44 \%$ of handovers, distractions in $52 \%$, no active inquiry in $43 \%$, no eye contact in $32 \%$ and no read back in $97 \%$. Despite these imperfections, the overall mean of the receivers' opinions of handover communication was high, that is 4.1 ( $\mathrm{SD} \pm 0.7$; scale $1-5$; 5 is excellent).

Other studies of handover communication show variable results in communicating the levels of SA. Ilan and colleagues conducted a descriptive study of the occurrence of the SBAR elements in medical handovers in an intensive care unit [38]. Regarding the first level of SA, the element situation was present in $98 \%$ of all handovers accounting for $16 \%$ of handover time, and the element background was present in $100 \%$ of handovers accounting for $56 \%$ of handover time. A study of Manser and colleagues showed that situation and background together account for $22 \%$ of postoperative handover time by both medical and nursing professionals [23]. Our findings show that professionals in perinatal and critical care are quite used to communicate level 1 of SA. Regarding the level 2 of SA, Ilan and colleagues found that the element assessment was present in nearly all handovers (98\%), which accounted for $20 \%$ of handover time. Also Manser and colleagues showed that in $20 \%$ of post-operative handover time an assessment was present. In our study, the element assessment was present in $24 \%$ of all handovers and in $37 \%$ of medical handovers. Apparently, professionals in perinatal care communicate level 2 of SA in fewer occasions than critical care professionals. A possible explanation might be that intensive care and operating room staff may generally be more focused on an assessment because they monitor multiple measurements of critically ill patients. Regarding the third level of SA, the element recommendation was present in $45 \%$ of handovers in the study of Ilan and colleagues accounting for $2 \%$ of handover time. In 
Poot, E.P., Bruijne, M.C. de, Wouters, M.G.A.J., Groot, C.J.M. de, Wagner, C. Exploring perinatath shift-to-shift handover communication and process: an observational study. Journal of

Evaluation in Clinical Practice: 2014, 20(2), 166-175

the study of Manser and colleagues, planning issues accounted for 9\% of handover time. In our study, presence of the element recommendation was present in $46 \%$ of all handovers and in 33\% of medical handovers. These findings show that professionals in both perinatal care and critical care are not used to extensive communication of level 3 of SA. Potentially, the relatively infrequent presence of the elements assessment (level 2) and recommendation (level 3) can be explained by senders assuming that the receivers will achieve the same assessment and recommendation by hearing the situation and background, as suggested by a study in aviation [10]. Another cause may be culture, for instance when senders believe that prompting an assessment or a recommendation show professional disrespect to the receivers. In general, the absence of the elements assessment and recommendation in a handover is a lack of communicating the more advanced levels of SA, that is interpretation of the data, anticipating future events and planning further actions. Furthermore, it limits collaborative cross-checking during handovers, which is described as a function of an adequate handover [18, 39]. In the studies of Ilan and colleagues and Manser and colleagues it is not clear how often all SBAR elements were present in handovers. In our study this was the case in $7 \%$ of handovers. This finding indicates that perinatal handover communication does not fully support situation assessment.

One study found similar findings for the heterogeneous pattern in the order of SBAR elements [38]. They also demonstrated a heterogeneous handover communication pattern assessed with the subjective, objective, assessment and plan framework. This suggests that health care professionals are not used to, or have difficulties in, structuring and standardizing handover communication during handovers regarding the order of the levels of SA.

Other studies regarding handover process show variable results. Regarding the duration of handovers our study fits in the range reported by other studies (96 seconds-3 minutes) in acute care settings [38, 40-43]. Compared with the lower limit of this range, our average duration may potentially be further reduced. This might be valuable in relation to situation assessment as long duration can lead to an overload of information, possibly leading to missing relevant data or inadequate interpretation of data and finally, a less adequate SA [17]. It is a challenge for each setting to find out which information is relevant to establish an adequate SA during handover [17]. Regarding active inquiry two studies showed that questions were asked in about 95\% of intensive care shift-to-shift patient handovers and of patient handovers from ambulance to an emergency department $[38,40]$. This rate was far higher than in our study. In general, active inquiry will contribute to situation assessment. For example, the receiver asking for clarification of vague information or additional information, for example an assessment (level 2) or treatment options (level 3). However, it is difficult to state that active inquiry is always necessary for situation assessment. For example, when the receiver assesses handover communication as clear and complete. When observing handovers, it is recommended to gather additional data about active inquiry, for example the nature of the question, that is whether it is clarifying, explorative or confirming, and the timing of the question.

Similar to our findings, a study by Greenstein and colleagues found that reading information back was present in a minority (17\%) of medical and multidisciplinary handover meetings in an internal medicine setting [43]. Also, Manser and colleagues found that $0.2 \%$ of handover time accounted for verifying information [23]. In our 
Poot, E.P., Bruijne, M.C. de, Wouters, M.G.A.J., Groot, C.J.M. de, Wagner, C. Exploring perinatath shift-to-shift handover communication and process: an observational study. Journal of Evaluation in Clinical Practice: 2014, 20(2), 166-175

study, health care professionals reported resistance against reading information back because they reported that it may be perceived as 'patronizing'.

Our results about receivers' opinions showed that handover communication was highly appraised, in contrast with the imperfections we measured in handover communication and process. A possible explanation might be that the receivers are used to current practice and are not fully aware that handover communication and process may influence situation assessment. This is suggested by our finding that receivers stated that actions needed for the patient were clear, whereas a recommendation was made in less than half of handovers. Presumably receivers deduce actions from the received information, also when this information is handed over implicitly rather than explicitly. Another explanation might be that receivers' opinions were measured directly after the handover meetings, at a stage when they were not yet aware of any imperfection of handover communication. A third explanation might be that the six-item questionnaire failed to detect existing differences in receivers' opinions in relation to situation assessment because 4 out of 6 items resembles SA level 1.

We found that the receivers' opinions of handover communication were more positive if the information was handed over in an orderly manner by clinically more experienced senders. One study [24] found similar findings by reporting that the overall assessment, and the sub-domains of senders' communication skills and content of the information, of nursing handovers in a medical, surgical and cardiovascular setting were positively influenced if senders were more experienced ( $>5$ years). However, the underlying mechanisms regarding this remain unclear. This study has some limitations. Handovers were observed by only one observer, which is may be less reliable than two or more independent observers; however, no interobserver variation occurred. To overcome possible bias, an observation protocol was developed and regularly discussed with colleagues. The definitions in the observation protocol were fine-tuned during the observation period through the addition of examples. Another limitation is that our observations protocol and checklist were not yet validated. This was something we had no control over because, at the time of measurement, the published instruments [20,22, 44] were not developed for measuring handover communication and process of individual patients in relation to situation assessment. Our explicit observation protocol facilitates validation in future research. Another limitation was that the sample size was too small to detect any confounding variables. For example, there may be an interaction between time of handover and clinical experience because more experienced professionals handed over in the morning than in the afternoon. Finally, our study had limited power and was restricted to shift-to-shift handovers during office hours. This limits the generalizability to all handovers of the labour ward under study and other (labour) wards in general. However, we believe that the adoption of the observed SBAR elements in our setting is similar to those in other Dutch perinatal services, because recommendations to use SBAR were only recently published [45]. In addition, the results of our study match with findings of the only other study we found on the presence of SBAR elements [38].

Few studies have been published on current handover practices, and none at all in a perinatal setting. This study provides insight into current perinatal handovers, and highlights the barriers to implement a handover that supports situation assessment. Our results may help to better prepare and manage the implementation of a handover 
Poot, E.P., Bruijne, M.C. de, Wouters, M.G.A.J., Groot, C.J.M. de, Wagner, C. Exploring perinatgh shift-to-shift handover communication and process: an observational study. Journal of Evaluation in Clinical Practice: 2014, 20(2), 166-175

ultimately leading to better patient safety by increasing shared SA. Exploring nivel handovers in this way contributes to a teamwork approach of handovers, which was recently recommended as a new approach in handover [18, 22].

Our results showed that situation assessment during perinatal shift-to-shift handovers is threatened by not communicating all levels of SA, relatively long handovers with distractions and frequent absence of active inquiry, eye contact and read back. This may lead to an inadequate SA in receivers of handover. However, staff members involved with handovers do not appear to be aware of this. Therefore, before implementing optimized handover communication and process, a sense of urgency needs to be created that improvement is necessary. This can be achieved by a 4-hour team resource management training in which lectures, reflecting on video material of current imperfect handovers and practising handovers supporting situation assessment by role playing [46-48] are present. Also, providing performance feedback after direct observations can contribute to more awareness [46]. Subsequently, an appropriate step would be to train and educate staff in a standardized communication tool to structure and shorten handover communication by using all levels of SA, and also by minimizing distractions, maximizing eye contact and explicitly reserving (sufficient) time for active inquiry and read back.

\section{CONCLUSION}

In our study, communication during perinatal shift-to-shift handover lacked transfer of assessment and recommendation in the majority of cases. Moreover, handover process was hampered by frequent disruptions and long duration as well as lack of active inquiry and read back. However, the receiver's of handover were very positive about handover communication, indicating a lack of awareness that patient safety is threatened during handover. Before future improvements can succeed, staff's awareness of current limitations should be increased by reflection and training.

\section{ACKNOWLEDGEMENTS}

We thank all staff of the Department of Obstetrics and Gynaecology of VU University Medical Centre in Amsterdam, the Netherlands, for their kind cooperation in gathering the data for this study.

\section{REFERENCES}

1EURO-PERISTAT Project in association with SCPE EE (2008) European perinatal health report. Euro-peristat.

2Mohangoo, A. D., Buitendijk, S. E., Hukkelhoven, C. W., Ravelli, A. C., Rijninks-van Driel, G. C., Tamminga, P. \& Nijhuis, J. G. (2008) [Higher perinatal mortality in The Netherlands than in other European countries: the Peristat-II study]. Nederlands Tijdschrift Voor Geneeskunde, 152 (50), 2718-2727.

3Steering committee pregnancy and birth (2009) A Good Start. Safe Care during Pregnancy and Birth. Utrecht: Steering committee pregnancy and birth.

4Pezzolesi, C., Schifano, F., Pickles, J., Randell, W., Hussain, Z., Muir, H. \& Dhillon, S. (2010) Clinical handover incident reporting in one UK general hospital. International Journal for Quality in Health Care, 22 (5), 396-401. 
Poot, E.P., Bruijne, M.C. de, Wouters, M.G.A.J., Groot, C.J.M. de, Wagner, C. Exploring perinatah shift-to-shift handover communication and process: an observational study. Journal of Evaluation in Clinical Practice: 2014, 20(2), 166-175

5Ravelli, A. C., Eskes, M., Tromp, M., van Huis, A. M., Steegers, E. A., Tamminga, P. \& Bonsel, G. J. (2008) [Perinatal mortality in The Netherlands 2000-2006; risk factors and risk selection]. Nederlands Tijdschrift Voor Geneeskunde, 152 (50), 2728-2733.

6Arora, V., Johnson, J., Lovinger, D., Humphrey, H. J. \& Meltzer, D. O. (2005) Communication failures in patient sign-out and suggestions for improvement: a critical incident analysis. Quality and Safety in Health Care, 14 (6), 401-407.

7Greenberg, C. C., Regenbogen, S. E., Studdert, D. M., Lipsitz, S. R., Rogers, S. O., Zinner, M. J. \& Gawande, A. A. (2007) Patterns of communication breakdowns resulting in injury to surgical patients. Journal of the American College of Surgeons, 204 (4), 533-540.

8Rabol, L. I., Andersen, M. L., Ostergaard, D., Bjorn, B., Lilja, B. \& Mogensen, T. (2011) Descriptions of verbal communication errors between staff. An analysis of 84 root cause analysis-reports from Danish hospitals. BMJ Quality and Safety, 20 (3), 268-274.

9Thomas, M. J., Schultz, J., Hannaford, N. \& Runciman, W. B. (2012) Failures in transition: learning from incidents relating to clinical handover in acute care. Journal for Healthcare Quality, 35 (3), 49-56.

10Wright, M. C. \& Endsley, M. R. (2008) Building shared situation awareness in healthcare settings. In Improving Healthcare Team Communication (ed. C. P. Nemeth ), pp. 97-114. Burlington: Ashgate publishing company.

11Edozien, L. C. (2011) Structured multidisciplinary intershift handover (SMITH): a tool for promoting safer intrapartum care. Journal of Obstetrics and Gynaecology, 31 (8), 683-686.

12Gosbee, J. (2010) Handoffs and communication: the underappreciated roles of situational awareness and inattentional blindness. Clinical Obstetrics and Gynecology, 53 (3), 545558.

13Mackintosh, N., Berridge, E. J. \& Freeth, D. (2009) Supporting structures for team situation awareness and decision making: insights from four delivery suites. Journal of Evaluation in Clinical Practice, 15 (1), 46-54.

14Endsley, M. R. (2000) Theoretical underpinning of situation awareness: a critical review. In Situation Awareness Analysis and Measurement (eds M. R. Endsley \& D. J. Garland ), pp. 3-32. Mahwah, NJ: Lawrence Erlbaum Associates.

15Raduma-Tomas, M. A., Flin, R., Yule, S. \& Close, S. (2012) The importance of preparation for doctors' handovers in an acute medical assessment unit: a hierarchical task analysis. BMJ Quality and Safety, 21 (3), 211-217.

16Staggers, N. \& Blaz, J. W. (2013) Research on nursing handoffs for medical and surgical settings: an integrative review. Journal of Advanced Nursing, 69 (2), 247-262.

17Endsley, M. R. (1995) Toward a theory of situation awareness in dynamic systems. Human Factors, 37 (1), 32-64.

18Manser, T. \& Foster, S. (2011) Effective handover communication: an overview of research and improvement efforts. Best Practice and Research. Clinical Anaesthesiology, 25 (2), 181-191.

19Pezzolesi, C., Manser, T., Schifano, F., Kostrzewski, A., Pickles, J., Harriet, N., Warren, I. \& Dhillon, S. (2013) Human factors in clinical handover: development and testing of a 'handover performance tool' for doctors' shift handovers. International Journal for Quality in Health Care, 25 (1), 58-65.

20Apker, J., Mallak, L. A., Applegate, E. B., III, Gibson, S. C., Ham, J. J., Johnson, N. A. \& Street, R. L., Jr (2010) Exploring emergency physician-hospitalist handoff interactions: development of the Handoff Communication Assessment. Annals of Emergency Medicine, 55 (2), 161-170.

210'Connell, B., Ockerby, C. \& Hawkins, M. (2013) Construct validity and reliability of the Handover Evaluation Scale. Journal of Clinical Nursing, [E-pub ahead of print] doi: 10.1111/jocn.12189.

22Manser, T., Foster, S., Gisin, S., Jaeckel, D. \& Ummenhofer, W. (2010) Assessing the quality of patient handoffs at care transitions. Quality and Safety in Health Care, 19 (6), e44.

23Manser, T., Foster, S., Flin, R. \& Patey, R. (2013) Team communication during patient handover from the operating room: more than facts and figures. Human Factors, 55 (1), 138-156. 
Poot, E.P., Bruijne, M.C. de, Wouters, M.G.A.J., Groot, C.J.M. de, Wagner, C. Exploring perinatah shift-to-shift handover communication and process: an observational study. Journal of Evaluation in Clinical Practice: 2014, 20(2), 166-175

24Horwitz, L. I., Dombroski, J., Murphy, T. E., Farnan, J. M., Johnson, J. K. \& Arora, V. M. (2012) Validation of a handoff assessment tool: the Handoff CEX. Journal of Clinical Nursing, 22 (9-10), 1477-1486.

25Endsley, M. R. Situation awareness and human error: designing to support human performance. Albuquerque, NM 1999.

26Riesenberg, L. A., Leisch, J. \& Cunningham, J. M. (2010) Nursing handoffs: a systematic review of the literature. The American Journal of Nursing, 110 (4), 24-34.

27 Wong, M. C., Yee, K. C. \& Turner, P. (2008) A structured evidence-based literature review regarding the effectiveness of improvement interventions in clinical handover. University of Tasmania, Australia: eHealth Services Research Group.

28Carroll, J. S., Williams, M. \& Gallivan, T. M. (2012) The ins and outs of change of shift handoffs between nurses: a communication challenge. BMJ Quality and Safety, 21 (7), 586-593.

29Riesenberg, L. A., Leitzsch, J., Massucci, J. L., Jaeger, J., Rosenfeld, J. C., Patow, C., Padmore, J. S. \& Karpovich, K. P. (2009) Residents' and attending physicians' handoffs: a systematic review of the literature. Academic Medicine, 84 (12), 1775-1787.

30Ong, M. S. \& Coiera, E. (2011) A systematic review of failures in handoff communication during intrahospital transfers. Joint Commission Journal on Quality and Patient Safety, 37 (6), 274-284.

31Australian Council for Safety and Quality in Healthcare (2005) Clinical handover and patient safety. Literature review report. Australian Council for Safety and Quality in Healthcare.

32Grol, R. \& Wensing, M. (2006) [Implementation. Effective Improvement of Patient Care]. Amsterdam: Elsevier Healthcare.

33Vanhaecht, K. \& Sermeus, W. (2006) Plan of action for the development, implementation and evaluation of a clinical pathway. 30 actions of the Clinical Pathway Network. Acta Hospitalia, 46 (3), 13-27.

34Merten, H., Lubberding, S., van Wagtendonk, I., Johannesma, P. C. \& Wagner, C. (2011) Patient safety in elderly hip fracture patients: design of a randomised controlled trial. BMC Health Services Research, 11, 59.

35Leonard, M., Graham, S. \& Bonacum, D. (2004) The human factor: the critical importance of effective teamwork and communication in providing safe care. Quality and Safety in Health Care, 13 (Suppl 1), i85-i90.

36Leonard, M. W. \& Frankel, A. S. (2011) Role of effective teamwork and communication in delivering safe, high-quality care. The Mount Sinai Journal of Medicine, 78 (6), 820-826.

37Hart, S. G. \& Staveland, L. E. (1988) Development of NASA-TLX (Task Load Index): results of empirical and theoretical research. In Human Mental Workload (eds P. A. Hancock \& N. Meshkati ), pp. 139-182. Amsterdam: North Holland Press.

38 llan, R., LeBaron, C. D., Christianson, M. K., Heyland, D. K., Day, A. \& Cohen, M. D. (2012) Handover patterns: an observational study of critical care physicians. BMC Health Services Research, 12, 11.

39Patterson, E. S., Woods, D. D., Cook, R. I. \& Render, M. L. (2007) Collaborative crosschecking to enhance resilience. Cognition, Technology and Work, 9, 155-162.

40ledema, R., Ball, C., Daly, B., Young J., Green T., Middleton P. M., Foster-Curry C., Jones M., Hoy S., Comerford D. (2012) Design and trial of a new ambulance-to-emergency department handover protocol: 'IMIST-AMBO'. BMJ Quality and Safety, 21 (8), 627-633. 41Symons, N. R., Wong, H. W., Manser, T., Sevdalis, N., Vincent, C. A. \& Moorthy, K. (2012) An observational study of teamwork skills in shift handover. International Journal of Surgery, 10 (7), 355-359.

42Rudiger-Sturchler, M., Keller, D. I. \& Bingisser, R. (2010) Emergency physician intershift handover - can a dINAMO checklist speed it up and improve quality? Swiss Medical Weekly, 140, w13085.

43Greenstein, E. A., Arora, V. M., Staisiunas, P. G., Banerjee, S. S. \& Farnan, J. M. (2012) Characterising physician listening behaviour during hospitalist handoffs using the HEAR checklist. BMJ Quality and Safety , 22 (3), 203-209.

44Nagpal, K., Abboudi, M., Fischler, L., Schmidt T., Vats A., Manchanda C., Sevdalis N., Scheidegger D., Vincent C. \& Moorthy K. (2011) Evaluation of postoperative handover 
Poot, E.P., Bruijne, M.C. de, Wouters, M.G.A.J., Groot, C.J.M. de, Wagner, C. Exploring perinatałh shift-to-shift handover communication and process: an observational study. Journal of Evaluation in Clinical Practice: 2014, 20(2), 166-175

using a tool to assess information transfer and teamwork. Annals of Surgery, 253 (4), 831 837.

45Dutch Perinatal Audit (2011) [Fetal and Neonatal Mortality of Term Birth 2010. First Exploration.]. Utrecht: Dutch Perinatal Audit Foundation.

46Haig, K. M., Sutton, S. \& Whittington, J. (2006) SBAR: a shared mental model for improving communication between clinicians. Joint Commission Journal on Quality and Patient Safety, 32 (3), 167-175.

47Carroll, T. L. (2006) SBAR and nurse-physician communication: pilot testing an educational intervention. Nursing Administration Quarterly, 30 (3), 295-299.

48ledema, R., Merrick, E. T., Kerridge, R., Herkes, R., Lee, B., Anscombe, M., Rajbhandari, D., Lucey, M. \& White, L. (2009) Handover - Enabling Learning in Communication for Safety (HELiCS): a report on achievements at two hospital sites. The Medical Journal of Australia, 190 (11 Suppl), S133-S136.

\section{TABLES AND FIGURES}

Box 1 Definitions of items observed during handovers

Observable item Description Examples

Handover communication

Situation Sender describes current patient's situation.

Background

Sender gives a statement of the relevant history of the patient.

Assessment

Recommendation

Handover process

Interruption

Distraction

Active inquiry

Eye contact

Read back
Sender's judgment of the current situation (interpretation) of the patient.

Sender describes what actions need to be performed in the next shift or describes conditions for a change of treatment.

Handover stops because the sender stops to communicate.

Presence of audible or visible stimuli not related to handover.

The receiver asks a patient-related question to clarify, explore or confirm information.

The sender and one or more receivers look each other in the eyes.

Receiver repeats information that was communicated.
The cervix is now about $6 \mathrm{~cm}$ dilated.

The woman has been pushing for half an hour.

The woman is waiting for a caesarean section.

Gravidity 4, Parity 3

Allergic to antibiotic $X$

History of intrauterine growth restriction

I conclude that active labour has started.

I think this woman has a pre eclampsia.

Re-evaluation of dilation at $1800 \mathrm{~h}$

Give medication $X$ at $1000 \mathrm{~h}$.

Contact anaes thetist for epidural pain relief.

Sender answers the telephone.

Telephone signals, staff walking in/out, answering the telephone (if not the sender), side conversations

What is the gestation period?

You said the gravidity was 2?

When was medical stimulation started?

No example required

The woman is in active labour with $6 \mathrm{~cm}$ dilation, is gravity 4 and parity 3 with a history of intrauterine growth restriction and I need to contact the anaesthetist for epidural pain relief. 
Poot, E.P., Bruijne, M.C. de, Wouters, M.G.A.J., Groot, C.J.M. de, Wagner, C. Exploring perinatah shift-to-shift handover communication and process: an observational study. Journal of Evaluation in Clinical Practice: 2014, 20(2), 166-175

Table 1 Characteristics of handovers by type and time of handover

\begin{tabular}{|c|c|c|c|c|c|c|c|c|c|c|c|c|c|c|c|}
\hline & & & & & & & Type & of handov & & & & Time & of handov & & \\
\hline & & & & All & lando & vers & Medi & ical & Nur: & sing & & Morn & ning & Afte & rnoon \\
\hline Item & & & & $n$ & $n(9$ & & $n$ & $n(\%)$ & $n$ & $n(9$ & & $n$ & $n(\%)$ & $n$ & $n(\%)$ \\
\hline Time of handover & $\begin{array}{l}\text { Mor } \\
\text { Afte }\end{array}$ & & & 70 & $\begin{array}{l}281 \\
421\end{array}$ & $\begin{array}{l}40.0) \\
60.0)\end{array}$ & 30 & $\begin{array}{l}13(43.3) \\
17(56.7)\end{array}$ & 40 & $\begin{array}{l}151 \\
251\end{array}$ & $\begin{array}{l}7.5) \\
2.5)\end{array}$ & - & $\begin{array}{l}- \\
-\end{array}$ & - & - \\
\hline Clinical experience of senders ${ }^{\dagger \neq}$ & $\begin{array}{l}<1 y \\
1-2 \\
3-4 \\
\geq 5 y\end{array}$ & & & 69 & $\begin{array}{r}51 \\
81 \\
121 \\
44(\end{array}$ & $\begin{array}{l}7.1) \\
11.6) \\
17.4) \\
63.8)\end{array}$ & 30 & $\begin{array}{r}5(16.7) \\
6(20.0) \\
8(26.7) \\
11(36.7)\end{array}$ & 39 & $\begin{array}{r}- \\
21 \\
41 \\
331\end{array}$ & $\begin{array}{l}0.1) \\
0.3) \\
4.6)\end{array}$ & 28 & $\begin{array}{l}- \\
- \\
6(21.4) \\
22(78.6)\end{array}$ & 41 & $\begin{array}{r}5(12.2) \\
8(19.5) \\
6(14.6) \\
22(53.7)\end{array}$ \\
\hline Type of disciplines of senders & $\begin{array}{l}\text { Juni } \\
\text { Clini } \\
\text { OB/ } \\
\text { OB/ } \\
\text { RN }\end{array}$ & $\begin{array}{l}\text { octor } \\
\text { nidwif } \\
\text { nurse } \\
\text { nurse }\end{array}$ & trainee & 69 & $\begin{array}{r}27 \\
31 \\
321 \\
51 \\
21\end{array}$ & $\begin{array}{l}39.1) \\
4.3) \\
46.4) \\
7.2) \\
2.9)\end{array}$ & 30 & $\begin{array}{l}27(90.0) \\
3(10.0) \\
- \\
- \\
-\end{array}$ & 39 & $\begin{array}{r}- \\
- \\
32 \\
5 \\
2\end{array}$ & $\begin{array}{l} \\
\text { 32.1) } \\
\text { (2.8) } \\
5.1)\end{array}$ & 28 & $\begin{array}{r}10(35.7) \\
3(10.7) \\
13(46.4) \\
2(7.1) \\
-\end{array}$ & 41 & $\begin{array}{l}17(41.4) \\
- \\
19(46.3) \\
3(7.3) \\
2(4.9)\end{array}$ \\
\hline Clinical experience of receivers ${ }^{59}$ & $\begin{array}{l}<1 y \\
1-2 \\
3-4 \\
\geq 5 y\end{array}$ & & & 51 & $\begin{array}{r}21 \\
31 \\
19 \\
27\end{array}$ & $\begin{array}{l}3.9) \\
5.9) \\
37.3) \\
52.9)\end{array}$ & 25 & $\begin{array}{c}2(8.0) \\
3(12.0) \\
11(44.0) \\
9(36.0)\end{array}$ & 26 & $\begin{array}{r}- \\
- \\
8 \\
18\end{array}$ & $\begin{array}{l} \\
30.8) \\
69.2)\end{array}$ & 23 & $\begin{array}{c}2(8.7) \\
3(13.0) \\
4(17.4) \\
14(60.9)\end{array}$ & 28 & $\begin{array}{l}- \\
- \\
15(53.6) \\
13(46.4)\end{array}$ \\
\hline Type of disciplines of receivers & $\begin{array}{l}\text { Juni } \\
\text { Clini } \\
\text { OB/ } \\
\text { OB/ } \\
\text { RN }\end{array}$ & $\begin{array}{l}\text { octor } \\
\text { nidwif } \\
\text { nurse } \\
\text { nurse }\end{array}$ & trainee & 51 & $\begin{array}{r}23 \\
21 \\
21 \\
1 \\
4\end{array}$ & $\begin{array}{l}45.1) \\
3.9) \\
41.2) \\
2.0) \\
7.8)\end{array}$ & 25 & $\begin{array}{l}23(92.0) \\
2(8.0) \\
- \\
- \\
-\end{array}$ & 26 & $\begin{array}{r}- \\
- \\
21 \\
1 \\
2\end{array}$ & $\begin{array}{l}30.8) \\
3.8) \\
3.7)\end{array}$ & 23 & $\begin{array}{c}6(26.1) \\
2(8.7) \\
12(52.2) \\
1(4.3) \\
2(8.7)\end{array}$ & 28 & $\begin{array}{l}17(60.7) \\
- \\
-9(32.1) \\
- \\
\quad 2(7.1)\end{array}$ \\
\hline & & Mea & (SD) & & Mea & (SD) & & Mear & SD) & & Mea & I (SD) & & Mea & (SD) \\
\hline $\begin{array}{l}\text { Number of health professionals pr } \\
\text { Bed utilization during handover }\end{array}$ & ent & $\begin{array}{l}66 \\
69\end{array}$ & $\begin{array}{l}9.7 \pm \\
4.3 \pm\end{array}$ & & $\begin{array}{l}30 \\
30\end{array}$ & $\begin{array}{r}10.2 \\
4.1\end{array}$ & $\begin{array}{l}( \pm 4.0) \\
( \pm 0.9)\end{array}$ & $\begin{array}{l}36 \\
39\end{array}$ & $\begin{array}{l}9.3(+ \\
4.4(+\end{array}$ & & $\begin{array}{l}27 \\
28\end{array}$ & $\begin{array}{r}12.3 \\
4.1\end{array}$ & $\begin{array}{l}3( \pm 2.9) \\
1( \pm 0.9)\end{array}$ & $\begin{array}{l}39 \\
41\end{array}$ & $\begin{array}{l}7.9( \pm 2.7) \\
4.4( \pm 0.9)\end{array}$ \\
\hline
\end{tabular}

$\mathrm{OB} / \mathrm{GYN}$, obstetrics and gynaecology; RN, registered nurse; SD, standard deviation.

*Night to day shift. **Day to evening shift. ***Number of beds on labour ward is 6 .

${ }^{+}$Significant for type of handover $P<0.000$ (Fisher's exact 18.179) and $P<0.000\left[\chi^{2}\right.$ trend 17.138; degrees of freedom (d.f.) $\left.=1\right]$.

'Significant for time of handover $P=0.007$ (Fisher's exact 11.15) and $P=0.04\left(\chi^{2}\right.$ trend 8.163; d.f. $=1$ ).

sSignificant for type of handover $P=0.025$ (Fisher's exact 7.648) and $P=0.005$ ( $\chi^{2}$ trend 7.923; d.f. = 1).

'Significant for time of handover $P=0.006$ (Fisher's exact 10.247); $\chi^{2}$ trend not significant. 
Table 2 Handover communication by type and time of handover

\begin{tabular}{|c|c|c|c|c|c|}
\hline Presence of SBAR elements & $\begin{array}{l}\text { All handovers } \\
(n=70) \\
n(\%)\end{array}$ & \multicolumn{2}{|c|}{ Type of handover } & \multicolumn{2}{|c|}{ Time of handover } \\
\hline \multicolumn{6}{|l|}{ Number of elements } \\
\hline One element & $3(4.3)$ & $2(6.7)$ & $1(2.5)$ & $1(3.6)$ & $2(4.8)$ \\
\hline Two elements & $31(44.3)$ & $12(40.0)$ & $19(47.5)$ & $12(42.9)$ & $19(45.2)$ \\
\hline \multicolumn{6}{|l|}{ Presence of separate elements } \\
\hline Current situation & $60(85.7)$ & $28(83.3)$ & $35(87.5)$ & $23(82.1)$ & $37(88.1)$ \\
\hline Background & $69(98.6)$ & $30(100)$ & $39(97.5)$ & $28(100.0)$ & $41(97.6)$ \\
\hline Assessment $^{\dagger}$ & $17(24.3)$ & $11(36.7)$ & $6(15.0)$ & $7(25.0)$ & $10(23.8)$ \\
\hline Recommendation & $32(45.7)$ & $10(33.3)$ & $22(55.0)$ & $13(46.4)$ & $19(45.2)$ \\
\hline $\mathrm{BR}$ & $10(14.3)$ & $3(10.0)$ & $7(17.5)$ & $3(10.7)$ & $7(16.7)$ \\
\hline
\end{tabular}

S, current situation; B, background; A, assessment; $\mathrm{R}$, recommendation.

*If order was present in $>10 \%$ of all handovers.

** Chronological sequence in time during handover (T1-T2), new moment defined as switch of element.

${ }^{\dagger}$ Significant for type of handover $P=0.036\left[\chi^{2} 4.377\right.$; degrees of freedom (d.f.) $\left.=1\right]$.

${ }^{ \pm}$Significant for type of handover : $P=0.006\left(\chi^{2} 7.565\right.$; d.f. $\left.=1\right)$. 
Table 3 Handover process of by type and time of handover

\begin{tabular}{|c|c|c|c|c|c|c|c|c|c|c|c|}
\hline \multirow[b]{3}{*}{ Item } & & & & \multicolumn{4}{|c|}{ Type of handover } & \multicolumn{4}{|c|}{ Time of handover } \\
\hline & & \multicolumn{2}{|c|}{ All handovers } & \multicolumn{2}{|c|}{ Medical } & \multicolumn{2}{|c|}{ Nursing } & \multicolumn{2}{|c|}{ Morning } & \multicolumn{2}{|c|}{ Afternoon } \\
\hline & & $n$ & $n(\%)$ & $n$ & $n(\%)$ & $n$ & $n(\%)$ & $n$ & $n(\%)$ & $n$ & $n(\%)$ \\
\hline \multirow[t]{5}{*}{ Duration* } & $<1$ minute & 66 & $13(19.7)$ & 27 & $5(18.5)$ & 39 & $8(20.5)$ & 27 & $7(25.9)$ & 39 & $6(15.4)$ \\
\hline & $1 \geq$ minutes $<2$ & & $24(36.4)$ & & $10(37.0)$ & & $14(35.9)$ & & $11(40.7)$ & & $13(33.3)$ \\
\hline & $2 \geq$ minutes $<3$ & & $15(22.7)$ & & $6(22.2)$ & & $9(23.1)$ & & $7(25.9)$ & & $8(20.5)$ \\
\hline & $3 \geq$ minutes $<4$ & & $8(12.1)$ & & $4(14.8)$ & & $4(10.3)$ & & $1(3.7)$ & & $7(17.9)$ \\
\hline & $\geq 4$ minutes & & $6(9.1)$ & & $2(7.4)$ & & $4(10.3)$ & & $1(3.7)$ & & $5(12.8)$ \\
\hline \multirow[t]{4}{*}{ Interruptions/distractions ${ }^{\dagger \ddagger}$} & 0 & 65 & $31(47.7)$ & 30 & $13(43.3)$ & 35 & $18(51.4)$ & 28 & $18(64.3)$ & 37 & $13(35.1)$ \\
\hline & 1 & & $24(36.9)$ & & $12(40.0)$ & & 12 (34.3) & & $8(28.6)$ & & $16(43.2)$ \\
\hline & 2 & & $8(12.3)$ & & $3(10.0)$ & & $5(14.3)$ & & $2(7.1)$ & & $6(16.2)$ \\
\hline & $\geq 3$ & & $2(3.0)$ & & $2(6.6)$ & & - & & - & & $2(5.4)$ \\
\hline \multirow[t]{2}{*}{ Asking questions ${ }^{\mathfrak{s}}$} & Yes & 64 & $36(56.3)$ & 27 & $18(66.7)$ & 37 & $18(48.6)$ & 25 & $10(40.0)$ & 39 & $26(66.7)$ \\
\hline & No & & $28(43.8)$ & & $9(33.3)$ & & $19(51.4)$ & & $15(60.0)$ & & 13 (33.3) \\
\hline \multirow[t]{3}{*}{ Regular eye contact } & Yes & 50 & $10(20.0)$ & 26 & $5(19.2)$ & 24 & $5(20.8)$ & 20 & $3(15.0)$ & 30 & $7(23.3)$ \\
\hline & Partly & & $24(48.0)$ & & $15(57.7)$ & & $9(37.5)$ & & $13(65.0)$ & & $11(36.7)$ \\
\hline & No & & $16(32.0)$ & & $6(23.1)$ & & $10(41.7)$ & & $4(20.0)$ & & $12(40.0)$ \\
\hline \multirow[t]{2}{*}{ Read back } & Yes & 70 & $2(2.9)$ & 30 & $2(6.7)$ & 40 & - & 28 & - & 42 & $2(4.8)$ \\
\hline & No & & $68(97.1)$ & & $28(93.3)$ & & $40(100.0)$ & & $28(100)$ & & 40 (95.2) \\
\hline
\end{tabular}

* Significant trend for time of handover $P=0.043\left(\chi^{2}\right.$ trend 4.085$)$.

'Presence of interruptions/distractions significant for time of handover $P=0.012\left[\chi^{2} 6.281\right.$; degrees of freedom (d.f.) $\left.=1\right]$.

${ }^{\ddagger}$ Number of interruptions/distractions significant trend for time of handover $P=0.019\left(\chi^{2}\right.$ trend 5.542).

${ }^{5}$ Significant for time of handover $P=0.036\left(\chi^{2} 4.402\right.$; d.f. $\left.=1\right)$. 
Poot, E.P., Bruijne, M.C. de, Wouters, M.G.A.J., Groot, C.J.M. de, Wagner, C. Exploring perinatał shift-to-shift handover communication and process: an observational study. Journal of Evaluation in Clinical Practice: 2014, 20(2), 166-175

Table 4 Assessment of handover communication by the receivers by type and time of handover

\begin{tabular}{|c|c|c|c|c|c|c|c|c|c|c|c|}
\hline \multirow[b]{3}{*}{ Sub-items } & \multirow{2}{*}{\multicolumn{3}{|c|}{ All handovers }} & \multicolumn{4}{|c|}{ Type of handover } & \multicolumn{4}{|c|}{ Time of handover } \\
\hline & & & & \multicolumn{2}{|c|}{ Medical } & \multicolumn{2}{|c|}{ Nursing } & \multicolumn{2}{|c|}{ Morning } & \multicolumn{2}{|c|}{ Afternoon } \\
\hline & & $n$ & $n(\%)$ & $n$ & $n(\%)$ & $n$ & $n(\%)$ & $n$ & $n(\%)$ & $n$ & $n(\%)$ \\
\hline \multirow[t]{5}{*}{ Information is complete } & $A$ & 51 & - & 25 & - & 26 & - & 23 & - & 28 & - \\
\hline & $B$ & & $1(2.0)$ & & - & & $1(3.8)$ & & $1(4.3)$ & & - \\
\hline & $\mathrm{C}$ & & $10(19.6)$ & & $6(24.0)$ & & $4(15.4)$ & & $4(17.4)$ & & $6(21.4)$ \\
\hline & $\mathrm{D}$ & & $27(52.9)$ & & $16(64.0)$ & & $11(42.3)$ & & $11(47.8)$ & & $16(57.1)$ \\
\hline & $E$ & & $13(25.5)$ & & $3(12.0)$ & & $10(38.5)$ & & $7(30.4)$ & & $6(21.4)$ \\
\hline \multirow{5}{*}{$\begin{array}{l}\text { Information presented in an } \\
\text { orderly manner }\end{array}$} & A & 51 & - & 25 & - & 26 & - & 23 & - & 28 & - \\
\hline & $B$ & & 2 (3.9) & & - & & $2(7.7)$ & & $2(8.7)$ & & - \\
\hline & $\mathrm{C}$ & & $11(21.6)$ & & $7(28.0)$ & & $4(15.4)$ & & $4(17.4)$ & & $7(25.0)$ \\
\hline & $\mathrm{D}$ & & $24(47.1)$ & & $14(56.0)$ & & $10(38.5)$ & & $9(39.1)$ & & 15 (53.6) \\
\hline & $E$ & & $14(27.5)$ & & $4(16.0)$ & & $10(38.5)$ & & $8(34.8)$ & & $6(21.4)$ \\
\hline \multirow{5}{*}{ Essential issues present } & A & 50 & - & 25 & - & 25 & - & 23 & - & 27 & - \\
\hline & $B$ & & $1(2.0)$ & & - & & - & & $1(4.3)$ & & - \\
\hline & $\mathrm{C}$ & & $10(20.0)$ & & $7(28.0)$ & & $3(12.0)$ & & $6(26.1)$ & & $4(14.8)$ \\
\hline & $\mathrm{D}$ & & $21(42.0)$ & & $12(48.0)$ & & $9(36.0)$ & & $6(26.1)$ & & $15(55.6)$ \\
\hline & $E$ & & $18(36.0)$ & & $6(24.0)$ & & $12(48.0)$ & & $10(43.5)$ & & $8(29.6)$ \\
\hline \multirow[t]{5}{*}{ Information is clear ${ }^{\dagger}$} & A & 51 & - & 25 & - & 26 & - & 23 & - & 28 & - \\
\hline & B & & $4(7.8)$ & & $1(4.0)$ & & $3(11.5)$ & & $3(13.0)$ & & 1 (3.6) \\
\hline & $\mathrm{C}$ & & 9 (17.6) & & $7(28.0)$ & & $2(7.7)$ & & $3(13.0)$ & & $6(21.4)$ \\
\hline & D & & 17 (33.3) & & $11(44.0)$ & & $6(23.1)$ & & $6(26.1)$ & & 11 (39.3) \\
\hline & $E$ & & $21(41.2)$ & & $6(24.0)$ & & $15(57.7)$ & & $11(47.8)$ & & $10(35.7)$ \\
\hline \multirow{5}{*}{ No unnecessary issues } & A & 51 & - & 25 & - & 26 & - & 23 & - & 28 & - \\
\hline & $B$ & & $6(11.8)$ & & $4(16.0)$ & & $2(7.7)$ & & $3(13.0)$ & & $3(10.7)$ \\
\hline & $\mathrm{C}$ & & $6(11.8)$ & & $3(12.0)$ & & $3(11.5)$ & & $1(4.3)$ & & $5(17.9)$ \\
\hline & $D$ & & $18(35.3)$ & & $9(36.0)$ & & $9(34.6)$ & & $8(34.8)$ & & $10(35.7)$ \\
\hline & $E$ & & $21(41.2)$ & & $9(36.0)$ & & $12(46.2)$ & & $11(47.8)$ & & $10(35.7)$ \\
\hline \multirow[t]{5}{*}{ Actions clear } & A & 50 & - & 25 & - & 25 & - & 22 & - & 28 & - \\
\hline & $B$ & & $1(2.0)$ & & $1(4.0)$ & & - & & - & & $1(3.6)$ \\
\hline & $\mathrm{C}$ & & $9(18.0)$ & & $6(24.0)$ & & $3(12.0)$ & & $3(13.6)$ & & $6(21.4)$ \\
\hline & $\mathrm{D}$ & & $20(40.0)$ & & $9(36.0)$ & & $11(44.0)$ & & $11(50.0)$ & & $9(32.1)$ \\
\hline & $\mathrm{E}$ & & $20(40.0)$ & & $9(36.0)$ & & $11(44.0)$ & & $8(36.4)$ & & 12 (42.9) \\
\hline \multirow[t]{2}{*}{ Overall assessment* } & Mean (SD) & 51 & $4.1( \pm 0.7)$ & 25 & $3.9( \pm 0.6)$ & 26 & $4.2( \pm 0.7)$ & 23 & $4.1( \pm 0.8)$ & 28 & $4.1( \pm 0.6)$ \\
\hline & Median & & 4.2 & & 4.0 & & 4.3 & & 4.2 & & 4.0 \\
\hline
\end{tabular}

A, strongly disagree; $B$, disagree; $C$, neutral; $D$, agree; $E$, strongly agree; $S D$, standard deviation.

* Mean of the mean score of all six sub-items in which $A=1, B=2, C=3, D=4$ and $E=5$.

'Significant for type of handover $P=0.024$ (Fisher's exact 8.816). 